Please cite as:

Dolnicar, S. (2020). Sharing economy and peer-to-peer
accommodation-a perspective paper. Tourism Review.

DOI 10.1108/TR-05-2019-0197

\title{
Sharing economy and peer-to-peer accommodation A perspective paper
}

\author{
Sara Dolnicar \\ Tourism | UQ Business School | The University of Queensland | Australia
}

\section{Introduction}

Understanding the new phenomenon of trading travel-related services among peers is critically important: it has immediate implications on the profitability of the hospitality sector, and is causing wide-reaching structural changes across the entire tourism industry.

The trading of goods among non-commercial partners ('ordinary' people) is nothing new, of course. In the past, people used public notice boards or the classified section of the local newspaper. Today, the internet is the trading platform of choice, dramatically increasing the efficiency of transactions. Online trading of space has attracted by far the most attention. Trading space is not 'sharing' (as in 'sharing economy') because buyers pay to be able to stay at someone else's place. Trading space is also not 'collaboration' (as in 'collaborative consumption') because no joint work, no collaboration, occurs in the process. Rather, paid online peer-to-peer accommodation trading consists of a non-commercial provider (host) selling space suitable for short term accommodation to an end user (guest) in a direct interaction (Dolnicar, 2019, p. 248). Many companies have attempted to successfully facilitate paid online peer-to-peer accommodation trading, but only three - Airbnb, Homeaway and Booking.com - have established themselves as key players globally (Hajibaba \& Dolnicar, 2018).

The aim of this perspective paper is to provide a snapshot of key learnings about paid online peer-to-peer accommodation trading as it relates to tourism and hospitality, and to identify future research questions.

\section{Past perspective 75 years of developments 1946-2020}

Figure 1 offers an overview of research into peer-to-peer accommodation. The middle section relates directly to tourism and hospitality; the sides show topics studied in other fields. Darker areas have been studied more extensively than lighter areas. The frequencies underlying the shading in Figure 1 have been taken from Dolnicar (2019). 
At the centre of Figure 1 stands the business model of peer-to-peer accommodation facilitators and all (micro)enterpreneurs participating in the sector. While full analyses of business models are rare (e.g. Reinhold \& Dolnicar, 2018), much tourism and hospitality research offers descriptions and illustrations of parts of the business model.

The normalisation of peer-to-peer accommodation is creating competition for the established accommodation sector (e.g. Zervas, Proserpio \& Byers, 2017), most critically for providers at the lower end of the service spectrum (e.g. Guttentag \& Smith, 2017). Consequently, competition and fairness of competition (e.g. Gurran, 2018) have been extensively studied, with fairness closely related to discussions about guest and host safety (e.g. Kennedy, Jones \& Gielen, 2018).

Tax implications have also received a reasonable amount of attention, as has the potential of peer-traded spaces to attract new market segments or better cater to the need of existing market segments, such as the increasing number of families engaging in multi-generational travel (e.g. Kleeman, 2014). The need for regulation and the optimal nature of regulation has been debated publicly and among academics, with most destinations moving towards location-specific regulations to protect residents without sacrificing all the economic benefits of peer-to-peer accommodation.

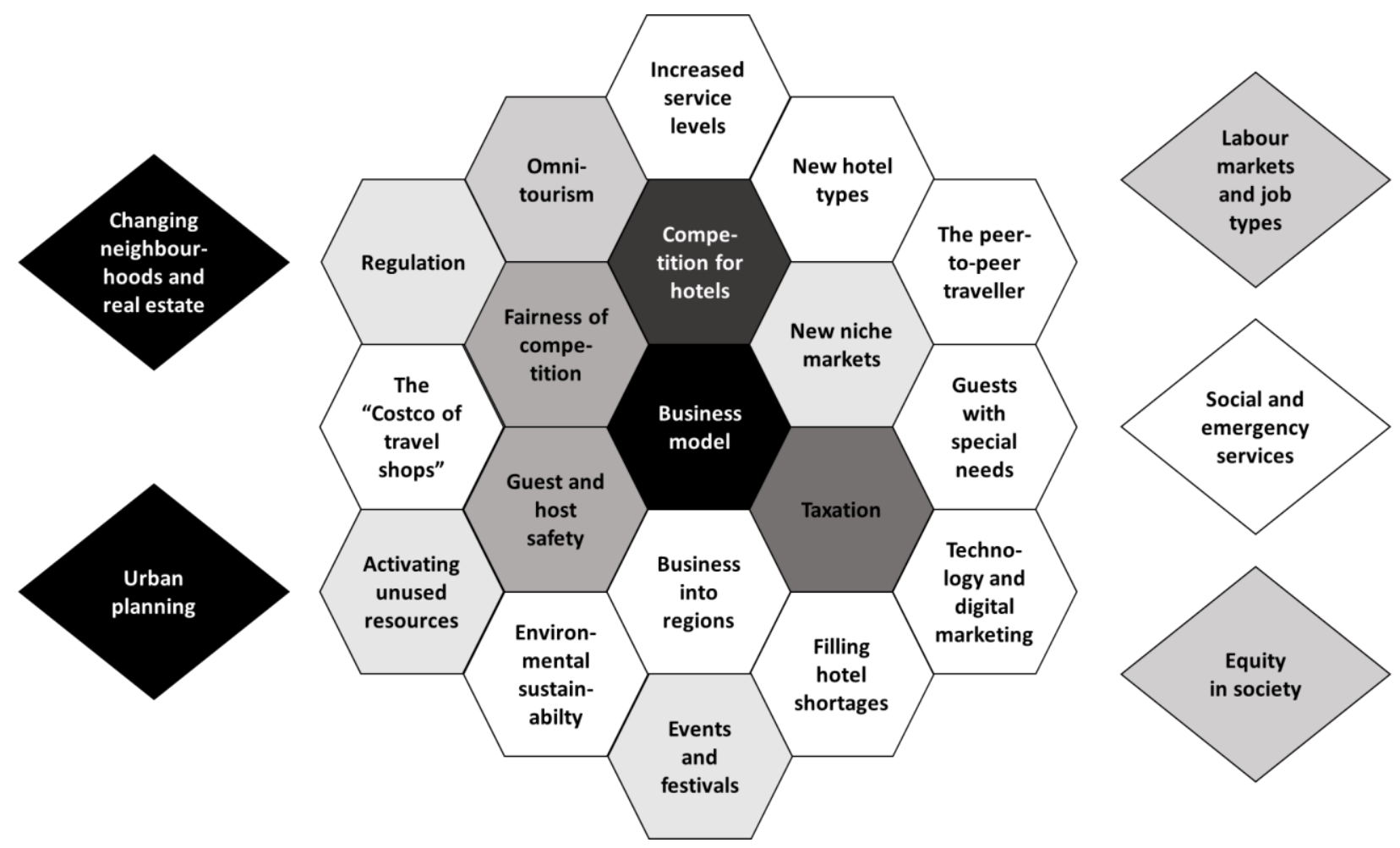

Figure 1. Research topics relating to paid online peer-to-peer accommodation.

The term omnitourism is used in Figure 1 to indicate that the use of residential properties leads to visitors no longer being confined to tourist areas at the destination, but rather being omnipresent, much to the dismay of some residents. Omnitourism can, but does not necessarily, go hand in hand with overtourism. 
The activation of unused resources is frequently mentioned, but rarely the main focus of investigation. Event organisers have already discovered the value of unused space made available by residents: it represent a low-cost approach to temporarily increasing much needed accommodation capacity (e.g. Fairley \& Dolnicar, 2018).

\section{Future perspective 75 years 2020-2095}

As Figure 1 shows, peer-to-peer trading in tourism offers a wide array of future topics for investigation, including the following:

- Will the normalisation of peer-traded spaces increase service expectations?

- Will hotels diversify to defend their market share?

- Will new trading platform facilitators emerge that will focus on genuine peer-to-peer trading only, rather than doubling up as a distribution channel for commercial accommodation and real estate investors?

- Will residents be able to find areas protected from omnitourism?

- Can we protect hospitality workers from the risk of non-permanent employment?

- What is the comparative environmental footprint of peer-to-peer accommodation (Chenoweth, 2009)? Can we make it even more environmentally friendly?

- How can we best leverage peer-traded spaces to:

○ meet the needs of travellers with impairments (Randle \& Dolnicar, 2019)?

○ strengthen rural/regional economies?

○ fill structural or temporary accommodation shortages?

○ assist people in need (e.g. victims of domestic violence)?

○ assist people displaced by natural disasters?

○ strengthen social tourism?

At a broader level, it will interesting to see if Airbnb, Homeaway and Booking.com will leverage their current market power as preferred providers of peer-to-peer accommodation to develop into the "Costcos of travel services" by selling anything travel-related (Gardiner \& Dolnicar, 2018). Equally interesting is the prospect of a new type of traveller developing: a traveller who purchases all travel-related services from peers only. A large-scale shift from tourism service provision by professionals to service provision by "amateurs" would mean a fundamental change of the very nature of the tourism industry as we know it.

\section{Conclusions}

Peer-to-peer trading of tourism-related products and services has the potential to radically alter how the tourism industry and the hospitality sector operate. An increase of non-professional service providers has a number of consequences: it opens entrepreneurial opportunities, while putting at risk reliable long-term employment with social benefits; increases choice for tourists and puts commercial providers under pressure to differentiate or improve their services; impacts on society through changes to residential neighbourhoods, changes in real estate markets, but 
also through the opportunity for increased inter-cultural understanding, potential for more social tourism, and the provision of emergency shelter for the most vulnerable members of society, including people displaced from their own homes by natural disaster and victims of domestic violence. More research is needed to ensure that the opportunities presented by peer-trading of travel-related services can be harvested to the benefit of economies, communities and people.

\section{References}

Chenoweth, J. (2009) Is tourism with a low impact on climate possible? Worldwide Hospitality and Tourism Themes, 1(3), 274-287.

Dolnicar, S. (2018) Peer-to-peer accommodation networks: pushing the boundaries. Oxford: Goodfellow Publishers.

Dolnicar, S. (2019) A review of research into paid online peer-to-peer accommodation. Annals of Tourism Research, 75, 248-264.

Fairley, S. \& Dolnicar, S. (2018) Supporting Events, in S. Dolnicar, Peer-to-peer accommodation networks, Oxford: Goodfellow Publishers, pp. 109-119.

Gardiner, S. \& Dolnicar, S. (2018) Networks becoming one-stop travel shops, in S. Dolnicar, Peer-to-peer accommodation networks, Oxford: Goodfellow Publishers, pp. 87-97.

Gurran, N. (2018) Global home-sharing, local communities and the Airbnb debate. Planning Theory \& Practice, 19(2), 298-304.

Guttentag, D.A. \& Smith, S.L. (2017) Assessing Airbnb as a disruptive innovation relative to hotels. International Journal of Hospitality Management, 64, 1-10.

Kleeman, G. (2014) Global tourism update. Geography Bulletin, 46(1), 17-23.

Hajibaba, H. \& Dolnicar, S. (2018) Airbnb and its competitors, in S. Dolnicar, Peer-to-peer accommodation networks, Oxford: Goodfellow Publishers, pp. 63-76.

Kennedy, H.R., Jones, V.C. \& Gielen, A. (2019) Reported fire safety and first-aid amenities in Airbnb venues in 16 American cities. Injury Prevention, 25(4), 328-330.

Randle, M. \& Dolnicar, S. (2019) Enabling people with impairments to use Airbnb. Annals of Tourism Research, 76:278-289.

Reinhold, S. \& Dolnicar, S. (2018b) Airbnb's business model, in S. Dolnicar, Peer-to-peer accommodation networks, Oxford: Goodfellow Publishers, pp. 27-38.

Zervas, G., Proserpio, D. \& Byers, J. W. (2017) The rise of the sharing economy: Estimating the impact of Airbnb on the hotel industry. Journal of Marketing Research, 54(5), 687-705. 